\title{
Correction to: Phloroglucinols from Myrtaceae: attractive targets for structural characterization, biological properties and synthetic procedures
}

\author{
Odeta Celaj - Alexandra G. Durán - Pasqualina Cennamo • \\ Monica Scognamiglio • Antonio Fiorentino • \\ Assunta Esposito - Brigida D'Abrosca (D)
}

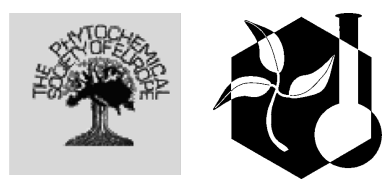

Published online: 9 September 2020

(C) Springer Nature B.V. 2020

\section{Correction to: Phytochem Rev https://doi.org/10.1007/s11101-020- 09697-2}

The original version of this article was missing an equal contribution statement. The first two authors (Odeta Celaj and Alexandra G. Durán) contributed equally to this work and are regarded as joint co-first authors.

Publisher's Note Springer Nature remains neutral with regard to jurisdictional claims in published maps and institutional affiliations.
The original article can be found online at https:// doi.org/10.1007/s11101-020-09697-2.

O. Celaj · P. Cennamo $\cdot$ M. Scognamiglio

A. Fiorentino · A. Esposito · B. D’Abrosca ( $\square)$ Dipartimento di Scienze e Tecnologie Ambientali Biologiche e Farmaceutiche -DiSTABiF, Università degli Studi della Campania "Luigi Vanvitelli", Via Vivaldi 43, 81100 Caserta, Italy

e-mail: brigida.dabrosca@unicampania.it

\section{A. G. Durán}

Allelopathy Group, Department of Organic Chemistry, Institute of Biomolecules (INBIO), Campus de Excelencia Internacional (ceiA3), School of Science, University of Cadiz, C/República Saharaui n ${ }^{\circ}$ 7, 11510 Puerto Real, Cadiz, Spain

\section{A. Fiorentino - B. D'Abrosca}

Dipartimento di Biotecnologia Marina, Stazione Zoologica Anton Dohrn, Villa Comunale, 80121 Naples, Italy 